\section{Administration of protein $C$ concentrates in patients without congenital deficit: a systematic review of the literature}

\author{
SIMONA SILVETTI • MARTINA CRIVELLARI • MARTA MUCCHETTI • \\ DAIANA TADDEO • ANNALISA FRANCO • GIOVANNI LANDONI • \\ ALBERTO ZANGRILLO
}

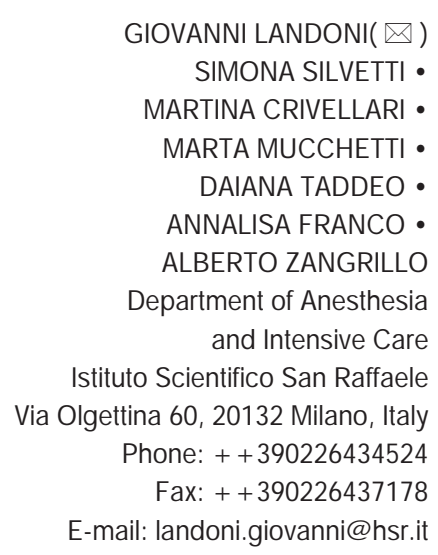

GIOVANNI LANDONI( $\square)$ SIMONA SILVETTI • MARTINA CRIVELLARI• MARTA MUCCHETTI • DAIANA TADDEO • ANNALISA FRANCO • ALBERTO ZANGRILLO Department of Anesthesia and Intensive Care Istituto Scientifico San Raffaele Via Olgettina 60, 20132 Milano, Italy Phone: ++390226434524

Fax: ++390226437178

E-mail: landoni.giovanni@hsr.it

\begin{abstract}
Endogenous protein $C$ levels are frequently decreased in septic patients, probably due to increased conversion to activated protein C. Protein C levels inversely correlate with morbidity and mortality of septic patients regardless of age, infecting microorganisms, presence of shock, disseminated intravascular coagulation, degree of hypercoagulation, or severity of illness. Taken together, these considerations suggest a strong correlation between protein $\mathrm{C}$ pathways and survival from severe sepsis/septic shock, and reinforce the rationale for the attempts to normalize plasma activity of protein $\mathrm{C}$ to improve survival, hamper coagulopathy, and modulate inflammation. We therefore conducted a systematic review of all manuscripts describing protein $\mathrm{C}$ concentrates administration in adult and pediatric populations. We identified 28 studies, for a total of 340 patients, 70 of whom died (20.6\%). Septic patients were the most represented in this review of case reports and case series. In the majority of these patients sepsis was associated with meningitis, purpura fulminans or disseminated intravascular coagulation. No bleeding complications related to the study drug were reported and most studies underlined normalization of inflammatory markers and of coagulation abnormalities. We conclude that protein $\mathrm{C}$ concentrate is an attractive option in septic patients (especially those with meningitis, purpura fulminans, or disseminated intravascular coagulation) and that its cost-benefit ratio must be studied with a large multicenter randomized control trial, possibly including also high risk patients with septic shock and multiple organ failure.
\end{abstract}

Key words: protein C zymogen, bleeding, amputations, intensive care, critical care.

\section{Introduction}

Sepsis is a highly complex process triggered by the release of numerous mediators that activate various defense systems, including the coagulation pathway. Severe sepsis and septic shock are life-threatening medical emergencies and are among the most significant challenges in critical care. Low endogenous protein $C(P C)$ levels are related to poor prognosis in patients with sepsis. (1) If low circulating PC levels could be restored to normal ones by infusion of exogenous PC, morbidity and mortality from sepsis might be reduced.

$\mathrm{PC}$ is a vitamin $\mathrm{K}$-dependent serine protease produced by the liver, present in the blood as a zymogen activated by thrombomodulin, a complex of thrombin and endothelial thrombin receptor, situated on the membrane of endothelial cells. Activated protein C (APC) exerts an anticoagulant effect and has anti-inflammatory and pro-fibrinolytic properties, preventing and reversing microvascular thrombus formation. (2) Survival Sepsis Campaign Guidelines recommend treatment strategies such as early-goal directed therapy and the use of recombinant human APC
(rhAPC). (3) Recently, the PROWESS SHOCK trial did not confirm the benefits of drotrecogin alfa (rhAPC), therefore the drug was withdrawn from the market because of limited efficacy and the presence of side effects (bleeding). Protein C concentrates (PCC) administration might be a useful alternative. (4) The safety and efficacy of intravenous or subcutaneous PCC for long-term prophylaxis in congenital PC deficiency is established since the year 1991. (5) Few authors have tested the utility of $P C C$ in young patients with purpura fulminans and/or meningitis and few reports exist on the use of $P C C$ as an alternative treatment to $\mathrm{rAPC}$ in adult 
patients affected by sepsis or septic shock, in which rhAPC was contraindicated by a high risk of bleeding.

We previously reviewed (6-8) the published experience with PCc in 66 adults (6-14) and 118 children (12-25) without congenital defects. Considering the market withdrawal of rhAPC, the recent publication of further case series (2629) and the presence of reports (30-33) that were not identified in the previous reviews, we decided to update the systematic review and concisely summarize the overall results.

\section{Materials and methods Search Strategy} BioMedCentral, PubMed, Embase and the Cochrane Central Register of Clinical Trials were searched for pertinent studies (updated October $1^{\text {st }}$, 2012) by three investigators. The search included the following terms: "protein C concentrate" or "protein C zymogen" or "Ceprotin". Further searches involved conference proceedings from pertinent congresses. The references of retrieved articles were carefully checked. No language restriction was enforced.

\section{Study Selection}

The search included the following terms: "protein C concentrate" or "protein C zymogen" or "Ceprotin". Identified citations were assessed on the basis of the title and abstract by two investigators; disagreementwas solved by consensus, with the supervision of a third investigator. Potentially eligible studies were retrieved in full. Relevant studies were included in this systematic review of whether they met the following inclusion criteria: a) administration of $\mathrm{PC}$; b) study performed in adult or pediatric patients; c) excluding congenital PCc deficiency. Data Abstraction and Study Characteristics

First author, year of publication, study design, number of patients, patient population, clinical setting, mortality, bleeding and number of amputations were independently extracted by two investigators.

\section{Results}

The systematic search initially identified

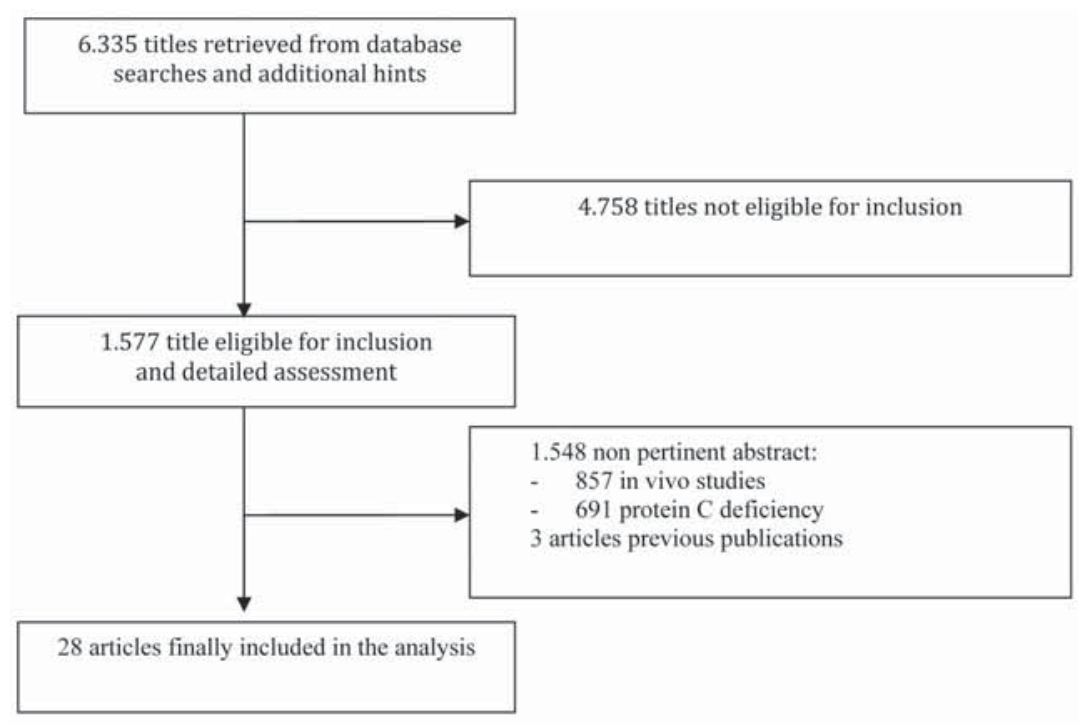

Figure 1. Flow chart on the selection of the papers that describe the use of Protein $\mathrm{C}$ concentrates in patients without Protein $\mathrm{C}$ deficiency.

a total of 6.335 titles (figure 1). Excluding 4.758 non-pertinent titles, we retrieved in complete form and assessed 1.577 studies according to the selection criteria. Excluding 1.548 non-pertinent abstracts, and 3 (34-36) were excluded because the data were already published in previous manuscripts, a total of 28 studies was finally selected, all of which described the administration of PCC in adult and pediatric populations without congenital deficits. The details of the 28 studies are reported in table 1.

A total of 340 patients (232 children and 108 adults) was included and the overall mortality rate was of $20,6 \%$ (70 patients). Only two studies were randomized $(20,28)$ while the others were case reports or case series, the largest study reporting 94 pediatric patients with purpura fulminans. (29) The studies were published between 1993 and 2012 , including mainly septic patients (94\%). Sepsis was associated with meningitis, purpura fulminans, and disseminated intravascular coagulation in most cases.

All papers but one (29) reported normalization of inflammatory markers and/or of coagulation abnormalities and/or improved outcome.

In 233 patients with purpura fulminans and/or meningitis, 26 amputations were described (11\%). One mild allergic reaction was reported as related to the study drug. No other adverse event related to PCC was reported among 340 patients.

Bleeding was reported as a complication only in two papers, $(20,29)$ but the authors specified that it was not related to $P C C$ administration. A randomized study performed in children described a mild gastrointestinal hemorrhage occurred in a patient who had severe disseminated intravascular coagulation (DIC) and died of septic shock one day later. (20) Veldman in his case series described two cases of bleeding: one patient developed epistaxis six hours after PCC administration, the other developed hemorrhage from the throat and the nose immediately after a difficult endotracheal intubation; both patients received the next dose of $\mathrm{PCC}$ without complications. (29)

\section{Discussion}

Protein $C$ concentrates administration has been safely reported in more than 300 patients without congenital PC deficiency. Most septic patients with or without meningitis had a normalization of laboratory find ings after PCC administration. When authors used a severity-ofdisease classification system, baseline 
Table 1. Summary of all published papers reporting on patients receiving protein $\mathrm{C}$ concentrates.

\begin{tabular}{|c|c|c|c|c|c|}
\hline Author & Setting & Patients & Deaths & Amputations & Predicted survival $\%$ \\
\hline Crivellari M & Sepsis/ septic shock & 9 & 1 & Non reported & SAPS II: $32 \%$ \\
\hline Landoni G & Sepsis/ septic shock & 2 & 0 & Non reported & \\
\hline Baratto F & Sepsis/ septic shock & 20 & 7 & Non reported & SAPS II: $41 \%$ \\
\hline Tuttolomondo A & Sepsis/ septic shock & 2 & 1 & Non reported & APACHE: $21 \%$ \\
\hline Pettenazzo A & Sepsis/ septic shock & 8 & 2 & 0 & PRISM: 56\% \\
\hline Silvani P & Sepsis/ septic shock & 11 & 3 & Non reported & \\
\hline De Carolis MP & Sepsis/ septic shock & 1 & 0 & Non reported & \\
\hline Betrosian AP & Sepsis/ septic shock & 3 & 0 & Non reported & \\
\hline BehrendtJ & Sepsis/ septic shock & 4 & 0 & Non reported & \\
\hline Morelli A & Sepsis/ septic shock & 18 & 0 & 0 & \\
\hline Ettingshausen CE & Meningococcal sepsis & 8 & 2 & 1 & \\
\hline Clarke RC & Meningococcal sepsis & 1 & 0 & Non reported & \\
\hline Leclerc F & Meningococcal sepsis & 1 & 0 & 1 & \\
\hline \multirow{2}{*}{ Smith OP } & \multirow{2}{*}{ Meningococcal sepsis } & \multirow{2}{*}{12} & \multirow{2}{*}{0} & \multirow{2}{*}{2} & GMSPS: $20 \%$ \\
\hline & & & & & PRISM: $43 \%$ \\
\hline Lignell A & Meningococcal sepsis & 1 & 0 & Non reported & \\
\hline Kreuz W & Meningococcal purpura & 7 & 2 & 1 & \\
\hline White B & Meningococcal purpura & 36 & 3 & 4 & GMSPS: $50 \%$ \\
\hline Fourrier F & Meningococcal purpura & 15 & 9 & 3 & PRISM: 31\% \\
\hline Vaccarella G & Meningococcal purpura & 1 & 0 & 0 & \\
\hline Gerson WT & Meningococcal purpura & 1 & 0 & 1 & \\
\hline Rivard GE & Meningococcal purpura & 4 & 0 & 2 & \\
\hline Ruffini E & Purpura fulminans & 4 & 0 & Non reported & \\
\hline $\begin{array}{l}\text { De Kleijn ED } \\
\text { Schellongowski P }\end{array}$ & $\begin{array}{l}\text { Purpura fulminans } \\
\text { Purpura fulminans }\end{array}$ & $\begin{array}{l}30 \\
8\end{array}$ & $\begin{array}{l}5 \\
2\end{array}$ & $\begin{array}{l}3 \\
2\end{array}$ & $\begin{array}{l}\text { PRISM: } 60 \% \\
\text { SAPS II: } 79 \%\end{array}$ \\
\hline Veldman A & Purpura fulminans & 94 & 21 & 5 & \\
\hline Rintala $\mathrm{E}$ & Purpura fulminans & 12 & 5 & 3 & \\
\hline Makris PE & DIC & 8 & 2 & Non reported & \\
\hline Malato A & DIC & 19 & 5 & Non reported & \\
\hline
\end{tabular}

APACHE, Acute Physiology and Chronic Health Evaluation; DIC, disseminated intravascular coagulation; GMSPS, Glasgow Meningococcal Septicaemia Prognostic Score; PRISM, Pediatric RIsk of Mortality; SAPS II, Simplified Acute Physiology Score.

scores generally indicated an expected mortality $(21-60 \%)$ higher than the overall observed mortality (20.6\%). All but three studies $(13,32,33)$ were of poor quality (abstract) and two thirds of the population was represented by children.

During severe sepsis, there is a reduction in PC concentration; PC correlates with increased morbidity and mortality. (1) Furthermore, in neonates PC levels reach the lower limit of normal adult levels (60-70\%) around 6-12 months of age, (37) thereby increasing the risk of coagulopathy in the pediatric septic population. Recombinant human APC was always contraindicated in children and therefore majority of the manuscripts of PCc in the literature concerns the pediatric population.

The published reports can be aggre- gated into three main groups: a) sepsis and septic shock (12 studies with 80 patients) b) purpura fulminans and/or meningitis (14 studies with 233 patients); c) DIC (2 studies with 27 patients).

A total of 12 studies (including 26 children and 54 adults) described sepsis or septic shock patients treated with PCC: 14 patients died; 5 children (19\% mortality) and 9 adults ( $17 \%$ mortality). The largest case series about PCc in sepsis has been published by Baratto et al. (7) They described the efficacy and safety of PCc to restore physiological values in 20 adult patients with severe sepsis or septic shock having clinical contraindications to treatment with rhAPC. Crivellari et al. (6) described their experience with the use of $\mathrm{PCC}$ in 9 adult patients with sepsis induced double organ failure after cardiac surgery. A pilot study (28) has reported the preliminary findings on the effect of PCC on microcirculatory blood flow in adult septic shock patients.

Protein C concentrates administrations in patients with purpura fulminans and/ or meningitis were described in 14 studies for a total of 233 patients (only 28 of them adults). Meningococcemia is the major infective cause of purpura fulminans, a devastating complication of uncontrolled systemic inflammation. It is characterized by thrombocytopenia, petechiae, and ecchymoses together with disseminated thrombosis of small vessels, resulting in tissue hypoperfusion, imminent peripheral gangrenes, and is associated with high incidence of amputations, skin grafts and death. 
Almost all these reports described a sudden improvement in the clinical picture with the use of $P C C$ in patients with purpura. The largest study in purpura fulminans patients was performed in a pediatric population of 94 children by Veldman. (29) This retrospective multicenter study showed that only few pediatric patients under PC treatment needed demato plasty and/or amputations, compared to historical controls. Apart from epistaxis (not related to the study drug), no bleeding was observed. A randomized phase 2, dose-finding study, was performed on 40 pediatric patients (30 receiving $P(C)$. This study showed a positive effect on sepsis induced coagulation abnormalities, but was not powered to show an effect on mortality rate. (20)
The less studied field was DIC. It is known that a pathogenetic mechanism of DIC is the reduction of protein C. In septic patients with DIC, substitution therapy with recombinant rhAPC has been proven to be effective, but with an increase in bleeding. In 2003 Makris and al. (13) treated 8 patients affected by overt DIC with PCC. Malato et al. (26) in 2011 described for the first time the role of PCC in 19 adult cancer patients with overtDIC. While non overt chronic DIC is quite common in cancer patients, there are no reliable data regarding the incidence and management of overt DIC. Malato et al. demonstrated the feasibility of PCC therapy for normalizing laboratory values and ameliorating the DIC score without bleeding or thrombosis.
Limitations

The main limitation of this systematic review is the poor quality of the included studies: all but two are non-randomized control trials (RTC).

\section{Conclusions}

Protein $C$ zymogen caused one mild allergic reaction and no bleeding in 340 patients with sepsis, purpura fulminans or DIC. Purpura fulminans in children is the most validated setting for the use of PCC in patients without congenital PC deficits, even if there is no randomized evidence to support survival benefits. Adult septic patients have a normalization of laboratory findings and a less than predicted mortality when receiving $\mathrm{PCC}$, but case match and RCTs are still missing.

\section{REFERENCES}

1. Fisher CJ, Yan SB. Protein C levels as a prognostic indicator of outcome in sepsis and related diseases. Crit Care Med 2000;28:S49-56.

2. Esmon $\mathrm{CT}$. Protein $\mathrm{C}$ anticoagulant pathway and its role in controlling microvascular thrombosis and inflammation. Crit Care Med 2001;29:S48-51.

3. Dellinger RP, Levy MM, Carlet J M, Bion J, Parker M. Surviving sepsis Campaign guidelines for management of severe sepsis and septic shock. Crit Care Med 2008;36:296-327.

4. Ranieri VM, Thompson BT, Barie PS, DhainautJ F, Douglas IS, Finfer S, et al. PROWESS-SHOCK Study Group. Drotrecogin Alfa (Activated) in Adults with Septic Shock. N EnglJ Med 2012;366:2055-64.

5. Dreyfus M, Magny J F, Bridey F, Schwarz HP, Planché C, Dehan M, et al. Treatment of homozygous protein C deficiency and neonatal purpura fulminans with a purified protein C concentrate. N EnglJ Med 1991;325:1565-8.

6. Crivellari M, Della Valle P, Landoni G, Pappalardo F, Gerli C, Bignami E, et al. Human protein C zymogen concentrates with severe sepsis and multiple organ failure after adult cardiac surgery. Intensive Care Med 2009;35:1959-63.

7. Baratto F, Michielan F, Meroni M, Dal Palù A, Boscolo A, Ori C. Protein C concentrate to restore physiological values in adult septic patients. Intensive Care Med 2008;34:1707-12.

8. Landoni G, Crivellari M, Monti G, Gerli C, Silvani P, Zangrillo A. Human protein C concentrates in adult septic patients. Signa vitae 2008;3:13-7.

9. XXTuttolomondo A, Pinto A, Di Raimondo D, Fernandez P, Licata G. Plasma derived protein C in severe sepsis: report of two cases. Intern Emerg Med 2008;3:179- 82.

10. Vaccarella G, Pelella R. Replacement treatment with protein C in an 18-year-old man with meningococcal sepsis and purpura fulminans. Minerva Anestesiol 2003;69:691- 3.

11. Rintala E, Kauppila M, Seppälä OP, Voipio-Pulkki LM, Pettilä V, Rasi V, et al. Protein C substitution in sepsis-associated purpura fulminans. Critical Care Med 200;28:2373-78.

12. Schellongowski P, Bauer E, Holzinger U, Staudinger T, Frass M, Laczika K, et al. Treatment of adult patients with sepsis-induced coagulopathy and purpura fulminans using a plasma-derived protein C concentrate (Ceprotin). Vox Sang 2006;90:294-301.

13. Makris PE, Girtovitis F, Papadopoulos A, Tamioulaki A, Kosmidou M, Pithara E. Treatment of DIC: the role of PC. J Thromb Haemost 2003;1(Suppl 1):abstract P0600.

14. Fourrier F, Leclerc F, Aidan K, Sadik A, J ourdain M, Tournoys A, et al. Combined antithrombin and protein C supplementation in meningococcal purpura fulminans: a pharmacokinetic study. Intensive Care Med 2003;29:1081-7.

15. Smith OP, White B, Vaughan D, Rafferty M. Use of protein-C concentrate, heparin, and haemodiafiltration in meningococcus-induced purpura fulminans. Lancet 1997;29:1590-3.

16. Gerson WT, Dickerman J D, Bovill EG, Golden E. Severe acquired protein C deficiency in purpura fulminans associated with disseminated intravascular coagulation: treatment with protein C concentrate. Pediatrics 1993;91:418-22.

17. Rivard GE, David M, Farrell C, Schwarz HP. Treatment of purpura fulminans in meningococcemia with protein C concentrate. J Pediatr 1995;126:646-52. 
18. Ettingshausen CE, Veldmann A, Beeg T, Schneider W. Replacement therapy with protein C concentrate in infants and adolescents with meningococcal sepsis and purpura fulminans. Semin Thromb Hemost 1999;25:537-41.

19. Clarke RC, J ohnston J R, Mayne EE. Meningococcal septicaemia: treatment with protein C concentrate. Intensive Care Med 2000; 26:471-3.

20. De Kleijn ED, De Groot R, Hack CE, Mulder PG, Engl W, Moritz B, et al. Activation of protein C following infusion of protein C concentrate in children with severe meningococcal sepsis and purpura fulminans: a randomized, double-blinded, placebo-controlled, dose-finding study. Crit Care Med 2003;31:1839-47.

21. Leclerc F, Cremer R, Leteurtre $S$, Martinot A, Fourier C. Protein C concentrate and recombinant tissue plasminogen activator in meningococcal septic shock. Crit Care Med 2000;28:1694-7.

22. White B, Livingstone W, Murphy C, Hodgson A, Rafferty M, Smith OP. An open-label study of the role of adjuvant hemostatic support with protein C replacement therapy in purpura fulminans-associated meningococcemia. Blood 2000;96:3719- 24.

23. Pettenazzo A, Malusa T. Use of protein C concentrate in critical conditions: clinical experience in pediatric patients with sepsis. Minerva Anestesiol 2004;70:357- 63.

24. Silvani P, Camporesi A, Licari E, Wolfler A. Use of protein C concentrate in pediatric patients with sepsis. Minerva Anestesiol 2005;71:373-8.

25. De Carolis MP, Polimeni V, Papacci P, Lacerenza S, Romagnoli C. Severe sepsis in a premature neonate: protein C replacement therapy. TurkJ Pediatr 2008;50:405-8.

26. Malato A, Saccullo G, Coco LL, Caracciolo C, Raso S, Santoro M, et al. Safety of plasma-derived protein C for treating disseminated intravascular coagulation in adult patients with active cancer. Am J Hematol 2011 Oct 31. doi: 10.1002/ajh.22238.

27. Betrosian AP, Memos N, Theoddossiades G, Douzinas EE. Protein C concentrate in adult septic patients. Intensive Care Med 2008;34:1932.

28. Morelli A, Donati A, Di Russo A, D'Ippolito F, Raffone C, D'Egidio A, et al. Human protein C concentrate to restore physiological values in adult septic shock patients: effects on microcirculation. Crit Care 2012;16 (Suppl 1):P201 doi: 10.1186/cc10808.

29. Veldman A, Fischer D, Wong FY, Kreuz W, Sasse M, Eberspächer B, et al. Human protein C concentrate in the treatment of purpura fulminans: a retrospective analysis of safety and outcome in 94 pediatric patients. Crit Care 2010;14: R156.

30. Kreuz W, Veldman A, Escuriola-Ettingshausen C, Schneider W, Beeg T. Protein-C concentrate for meningococcal purpura fulminans. Lancet 1998;351:986-7.

31. Lignell A, Siegbahn A, Stridsberg M, Pauksen K, Gedeborg R, Sjolin J. Low utilisation of unactivated protein C in a patient with meningococcal septic shock and disseminated intravascular coagulation. Acta Anaesthesiol Scand 2003;47:897-900.

32. Ruffini E, Osimani P, J orini M, Cordiali R, Pagni R, De Benedictis FM. Treatment of purpura fulminans with protein C concentrate: A further scientific evidence. Italian J ournal of Pediatrics 2004; 30:169-73.

33. Behrendt J Karpe J, Sadownik B, Wasek M, Godula-Stuglik U. Substitution of human protein C concentrates in the treatment of late-onset sepsis in preterm neonates (preliminary report). Pediatria polska 2005;124-28.

34. Rintala E, Kauppila M, Seppälä OP, Voipio-Pulkki LM, Pettilä V, Rasi V, et al. Protein C substitution in sepsis-associated purpura fulminans. Crit Care Med 1998;28:2373-8.

35. Baratto F, Michielan F, Gagliardi G, Di Gregorio G, Pasqualetto A, Meroni M, et al. Use of protein C concentrate in adult patients with severe sepsis and septic shock. Minerva Anestesiol 2004;70:351-6.

36. Fischer D, Schloesser RL, Nold-Petry CA, Nold MF, Veldman A. Protein C concentrate in preterm neonates with sepsis. Acta Pæliatrica ISSN 0803-5253

37. Andrew M, Paes B, J ohnston M. Development of the hemostatic system in the neonate and young infant. Am J Pediatr Hematol Oncol 1990;12:95-104. 